\title{
Análise de viabilidade econômica financeira para a implantação de uma central de massa em uma indústria cerâmica de Itaboraí, RJ
}

\author{
(Economic and financial feasibility analysis for central mass \\ implementation of a ceramic industry in Itaboraí, RJ, Brazil)
}

\author{
A. C. da Silva, A. J. C. Pithon, J. L. Fernandes, L. M. dos Santos \\ Programa de Pós-Graduação em Tecnologia, Centro Federal de Educação Tecnológica do Rio de Janeiro - \\ CEFET/RJ, Av. Maracanã 229, Bloco E, $5^{\circ}$ andar, Rio de Janeiro, RJ 20271-110 \\ acantareli@hotmail.com,caulliraux@gmail.com,jluizfernandes@gmail.com,dkpsantos@uol.com.br
}

\begin{abstract}
Resumo
Este trabalho apresenta um estudo de viabilidade econômico financeira para a implantação de uma central de massa, com o objetivo de preparar a argila antes do processo produtivo, utilizando-se de técnicas adequadas e apropriadas, que proporcionam economia de matéria-prima, redução do consumo de energia elétrica, redução do consumo de energia térmica, aumento da produtividade, entre outros benefícios. Foram realizadas simulações em três tipos de cenários: pessimista, mais provável e otimista. Utilizaram-se os métodos tradicionais de avaliação: VPL, TIR e Payback Descontado. Em todos os três cenários os resultados determinam que o investimento é viável.

Palavras-chave: cerâmica, bloco cerâmico, argila, análise de viabilidade econômica.
\end{abstract}

Abstract

This paper presents a study of economic and financial viability for central mass implementation, with the aim of preparing the clay before the production process, using appropriate techniques and fitting, that providing savings in raw materials, reduce the consumption electricity, reduction of thermal energy consumption, increased productivity, among other benefits. We simulated three types of scenarios: pessimistic, most likely and optimistic. We used the traditional assessment methods: NPV, IRR and Discounted Payback. In all three scenarios the results determine that the investment is viable.

Keywords: ceramics, ceramic block, clay, economic availability analysis.

\section{INTRODUÇÃO}

O segmento da indústria cerâmica no município fluminense de Itaboraí apresenta-se como um dos mais antigos da região, com origem segundo dados históricos na década de 1950. Até os dias atuais, o município de Itaboraí possui o maior segmento industrial e assim deverá continuar até o início das atividades do COMPERJ - Complexo Petroquímico do Rio de Janeiro, previstas para 2016, quando provavelmente estarão iniciando operações de empresas consumidoras da principal matéria prima a ser produzida, utilizada pelas indústrias de plásticos. A cidade que era considerada dormitório há cerca de cinco anos, quando boa parte de sua população ativa para o trabalho deslocava-se para as cidades de São Gonçalo, Niterói e Rio de Janeiro para trabalhar, hoje assiste um deslocamento em sentido contrário com a chegada de funcionários das construtoras do citado Complexo, bem como das outras obras, uma vez que não houve mão-de-obra local qualificada o suficiente para suprir a demanda. $O$ setor ceramista sofre com estas mudanças em alguns aspectos, dentre eles a evasão de funcionários para as construtoras que se instalaram na cidade, em especial a mão-de-obra mais qualificada como pedreiros, soldadores, motoristas, operadores de máquinas e tratores.
O setor é muito carente de mão-de-obra, pois não conta com sistemas automatizados de produção. A partir da chegada dos novos investimentos, a procura por grandes áreas de terras se acentuou e como boa parte do solo itaboraiense é argiloso, as indústrias cerâmicas passaram a ter outro problema: a possível escassez da matéria-prima. Importa destacar que as fábricas atuais não fazem nenhum beneficiamento da argila, utilizando-a imediatamente após a sua extração. Poucas fábricas deixam a argila estocada.

Como proposta para a solução da redução do consumo de argila ou aumento da produtividade nas fábricas, propõese uma análise de viabilidade econômico-financeira para a implantação de uma central de preparação de massa, como forma de melhoria da qualidade e produtiva dos produtos, através de um estudo de caso em indústria cerâmica no município de Itaboraí. Para tanto, faz-se necessário o entendimento do que vem a ser bloco cerâmico, processo de produção na indústria cerâmica e demais definições pertinentes à pesquisa.

\section{O bloco cerâmico}

Por bloco cerâmico entende-se o produto que tem como 


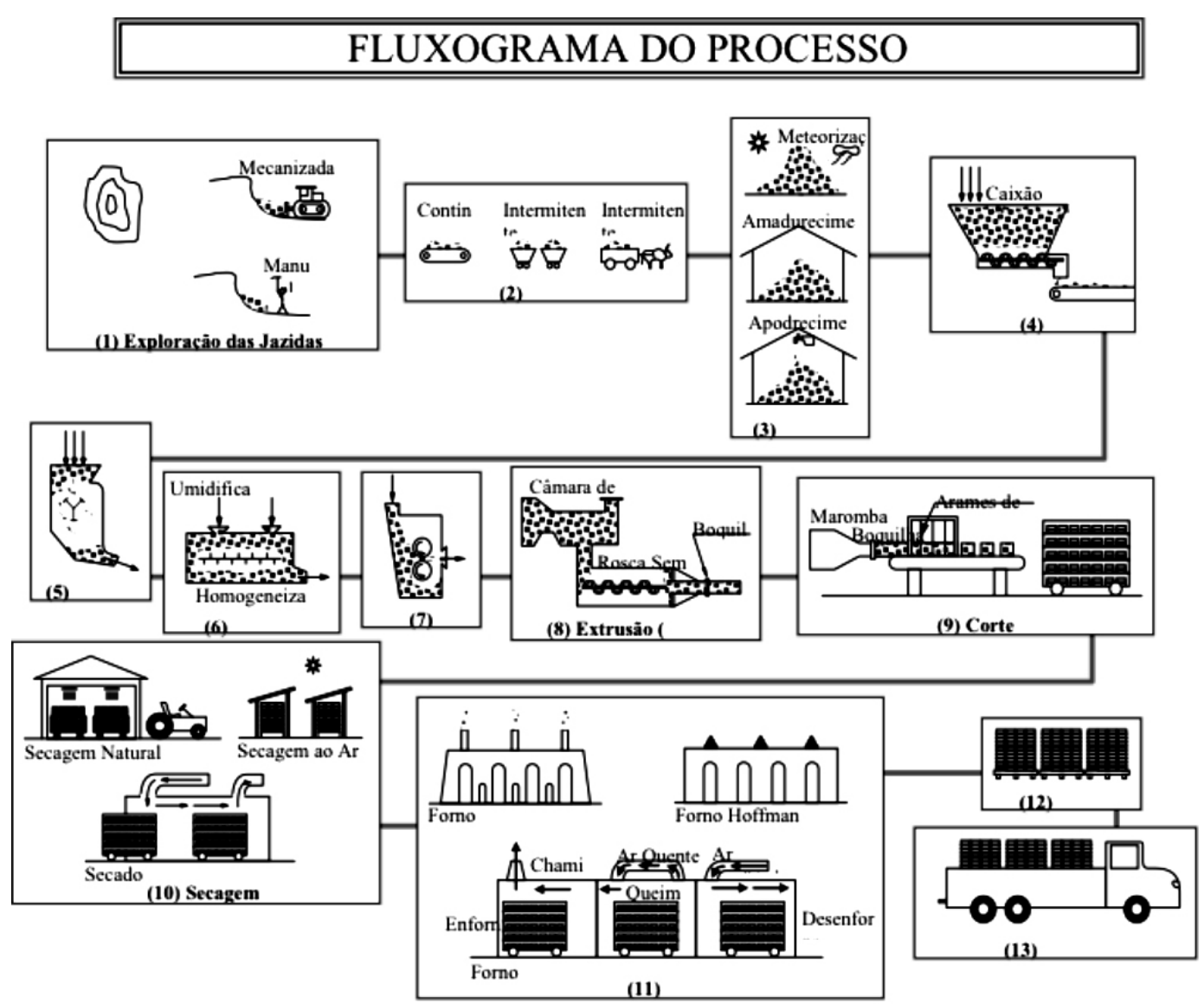

Figura 1: Fluxograma do processo cerâmico [5].

[Figure 1: Flowchart of the ceramic process [5].]

principal insumo a argila, que após processo específico de conformação e cozimento à temperatura adequada, alcança grau de resistência mecânica à compressão, ao desgaste e à umidade. Sua utilidade é a construção de paredes de alvenaria que podem ter as funções de vedação ou estrutural em obras, atendendo as demandas da construção civil tanto residencial, como comercial ou industrial. Sua utilização é em larga escala e seus tipos são diversos. Os blocos representam de 80 a $95 \%$ do volume da alvenaria, determinantes da maior parte das características da parede: "resistência à compressão, estabilidade e precisão dimensional, resistência ao fogo e à penetração de chuvas, isolamento térmico e acústico e estética" [1]. A norma ABNT NBR 15270-1 define bloco cerâmico de vedação como "componente da alvenaria de vedação que possui furos prismáticos perpendiculares às faces que os contém" [2]. São chamados de vedação porque não tem a função de suportar a carga referente à alvenaria em que são utilizados, "devendo resistir somente ao peso próprio e a pequenas cargas de ocupação" [3]. Podem ser utilizados tanto nas paredes externas quanto internas da construção. Outro tipo de bloco é denominado bloco cerâmico estrutural definido como o "componente da alvenaria estrutural que possui furos prismáticos perpendiculares às faces que os contém" [2]. Como o próprio nome determina, este tipo de bloco tem função estrutural, ou seja, tem a função de suportar a carga referente à alvenaria em que são utilizados. Também podem ser utilizados tanto em paredes externas quanto internas de uma construção, de acordo com as necessidades estruturais requeridas pelo projeto.

\section{Processo de produção na indústria cerâmica}

O processo de produção na indústria cerâmica se inicia na escolha das argilas que serão utilizadas em função do tipo de produto cerâmico que se pretende produzir. Destaca-se que a decisão de fabricação de qualquer produto implica em uma série de avaliações a serem tomadas.

A argila é o principal insumo para a fabricação de produtos cerâmicos, seja na indústria ou no artesanato. "O termo argila refere-se a um material de ocorrência natural, o qual é composto, primeiramente, por minerais de granulometria fina, os quais são geralmente plásticos com o apropriado teor de água e que endurecem quando secos ou calcinados" [4]. O modelo apresentado no fluxograma do processo conforme a Fig. 1 é um modelo geral do processo fabril nas indústrias cerâmicas.

Na fase 1 ocorre a exploração da jazida que atualmente é feita em sua maioria por equipamentos automotores, embora em regiões mais pobres a extração seja feita manualmente 
utilizando-se de picaretas, enxadas, enxadões e pás, e o transporte até à fabrica através de carrinhos de mão ou carroças com tração animal, realizando a fase 2. A fase 3 demonstra o estoque de argila que na maioria das fábricas é feito ao tempo sem qualquer tipo de preparação e o sazonamento é feito sem qualquer técnica de preparação de massa. Na seqüência vêm os equipamentos da linha de produção: caixão alimentador - fase 4; desintegrador - fase 5; homogeneizador - fase 6; laminador - fase 7; extrusora - fase 8; cortadeira - fase 9. Após a etapa da cortadeira os produtos cerâmicos seguem para a secagem que pode ser feita de duas formas: natural ou artificial. Em ambas, a atividade principal é eliminar água dos produtos permitindo assim que os mesmos possam ser encaminhados aos fornos. Dois tipos de água precisam ser expelidas no processo de secagem: água higroscópica, que vaporiza entre 50 e $200{ }^{\circ} \mathrm{C}$; e água interfoliar (lamelar), que vaporiza entre 250 e $650{ }^{\circ} \mathrm{C}$. A secagem natural consiste em encaminhar os produtos para galpões apropriados ou ao ar livre, onde são empilhados em leiras de forma que favoreça a passagem da ventilação. Este sistema pode ser bem lento em função das condições climáticas. Pode-se definir secagem natural como aquela que "é realizada nas peças cerâmicas, quando expostas à temperatura ambiente, por meio da movimentação natural do ar" [6]. Outra forma de realizar este processo é através da secagem artificial. A secagem artificial consiste na utilização de secadores para acelerar a extração de água dos produtos após a extrusão. São ambientes fechados onde os produtos são colocados utilizando-se normalmente de vagonetas específicas. A injeção de calor é feita através de exaustores, retirados da área de resfriamento dos fornos ou de fornalhas construídas para geração de calor. Para se retirar a umidade utiliza-se extratores de umidade posicionados de acordo com o projeto, normalmente da saída dos secadores. Um secador artificial não poderá ser feito sem antes se estudar a argila com a qual se trabalha a quantidade de produtos secos que se deseja ter e a forma de geração de calor a ser utilizada. Uma vez que os produtos estejam secos, independente da forma como a secagem é feita, se natural ou se artificial, os produtos cerâmicos serão encaminhados para a sinterização nos fornos. Sinterização é o processo químico pelo qual a argila modifica seu estado adquirindo resistência à compressão e à umidade. Este processo ocorre em fornos específicos podendo ser realizada a queima, como informalmente é conhecida a sinterização, de forma contínua ou intermitente. $\mathrm{O}$ sistema de queima contínua utiliza fornos com estrutura capaz de manter o fogo aceso sem interrupção, são chamados de fornos contínuos. Encontra-se no mercado os fornos Hoffman e túnel como os mais utilizados neste tipo de queima. O forno Hoffman, projeto alemão de 1850 , continua até os dias atuais sendo utilizado de forma muito freqüente nas cerâmicas. O processo de queima se dá através de câmaras onde são colocados os produtos cerâmicos empilhados de forma que favoreça a passagem do calor gerado pelo combustível que é introduzido no processo pelo teto do forno em aberturas apropriadas, e deslocado através de processo de exaustão. O sistema de queima intermitente trabalha com fornos onde as cargas são depositadas em câmaras específicas, também chamadas de sala de queima. Iniciando o aquecimento do forno, segue a sinterização propriamente dita até o resfriamento após o encerramento da mesma. No mercado encontram-se diversos fornos com este tipo de sistema dentre eles destacam-se: forno redondo, forno paulistinha, forno vagão, etc. $\mathrm{O}$ combustível utilizado no processo de queima é muito diverso. Cada região do país utiliza elementos que se encontram em maior oferta. Entre os mais utilizados encontram-se: madeira de reflorestamento, aparas de eucalipto, resíduos de madeira não contaminados, óleo combustível apropriado, GLP - gás liquefeito de petróleo, casca de arroz, serragem, GN - gás natural. Na região de Itaboraí utiliza-se com mais freqüência madeira de reflorestamento, resíduos de madeira não contaminados, aparas de eucalipto. Após a sinterização os produtos cerâmicos são encaminhados para a área de estocagem das fábricas onde são armazenados em pilhas. Algumas empresas utilizam sistema de paletização e carregamento com empilhadeiras. Em sua maioria, as fábricas carregam de forma manual os caminhões que realizam a entrega aos clientes.

\section{Preparação da massa argilosa}

A preparação de argila também chamada de preparação de massa argilosa ou simplesmente preparação de massa é um tipo de sazonamento das argilas utilizadas no processo de fabricação de blocos cerâmicos. Entende-se por sazonamento a forma como a argila é estocada, para que possa decompor os sais solúveis e matéria orgânica presentes na mesma [6]. O sazonamento é também conhecido como intemperismo, o que se refere à ação do sol, chuva e vento sobre a argila [7]. A importância de preparação da massa argilosa reside em vários aspectos destacando-se: a qualidade do produto, produtividade, redução do consumo energético na produção, redução de perdas, redução do consumo de argila [6]. Este último aspecto, redução do consumo de argila, no tocante à cidade de Itaboraí é o que justifica a adaptação da forma na qual a argila é recebida nas fábricas e também o melhor aproveitamento da mesma evitando desperdícios e aumentando a vida útil das jazidas, lembrando que o minério é um bem exaurível. A primeira etapa para a preparação é

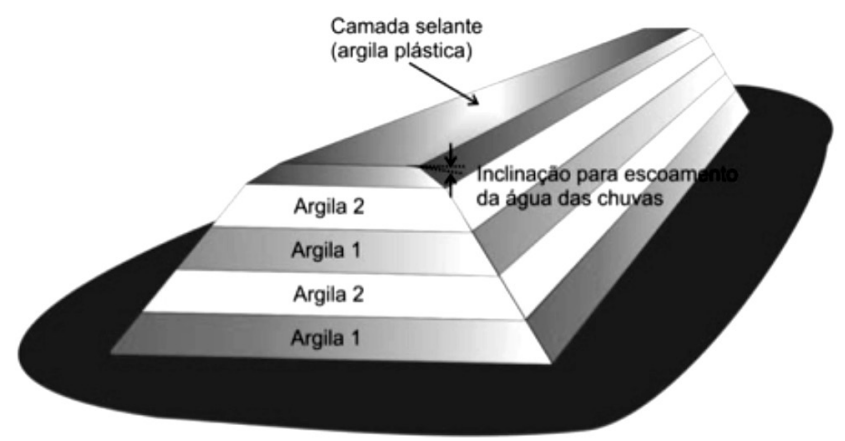

Figura 2: Estoque de argila em camadas [8]. [Figure 2: Stock of layered clay [8].] 
recolher amostras da argila ou das argilas por jazida para que suas características físicas e químicas sejam analisadas. Uma vez classificadas, as amostras das argilas devem ser testadas em laboratórios específicos. Utilizando quantidades distintas indicarão o uso mais apropriado das mesmas. Após a classificação as argilas poderão ser dispostas na fábrica de três formas: sanduíche, montes separados ou montes misturados, de acordo com o tipo de argila. Sanduíche seria a forma de estocar argila colocando uma camada de argila "1", outra camada de argila "2" e na seqüência outra camada de argila "1", intercalando-as, conforme Fig. 2. Os montes serão identificados com placas, de acordo com o tipo de argila ou mistura realizada [7], para uso futuro de acordo com a mistura que necessita para o tipo de produto a fabricar.

Todas as formas de preparação de massa produzem resultados eficientes, mas a boa qualidade da argila vai depender do período de sazonamento - quanto mais tempo, melhor a qualidade [7]. Havendo possibilidade as pilhas poderão ser cobertas ou estocadas em galpões que permitam a movimentação do material de acordo com as demandas de produção.

O transporte da argila até a área de estocagem nas fábricas é feita através de caminhões do tipo basculante, abastecidos por máquinas motrizes denominadas como páscarregadeiras. As fábricas poderão contar ainda com tratores de esteira para montarem as pilhas e organizar o estoque. A carga da argila no caixão alimentador é realizada por pás-carregadeiras para que o processo de destorroamento da argila possa acontecer. Destorroar é diminuir o tamanho do grão argiloso para que ele absorva melhor a água, permitindo melhor homogeinização da massa contribuindo para o aumento da plasticidade. O destorroador ou desagregador é um equipamento que tem por função triturar grandes terrões de argilas, sejam estas brandas ou duras, objetivando a uniformidade granulométrica o que favorecerá a eficiência dos alimentadores, que deverá sempre ser contínua e homogênea. Composto de dois cilindros com discos ou pratos de aço ambos substituíveis, é composto ainda de martelos postiços desmontáveis. Os cilindros giram em sentido inverso e com velocidades diferentes [8]. A preparação de argila conta ainda com outra forma de realização do processo que é a moagem através de moinhos de martelo e que podem ser feitas de três formas: moagem por via semi-úmida, moagem por via seca e moagem por via úmida utilizando moinho de bolas $[8,9]$ declara que

"os materiais soltos, facilmente friáveis, plásticos, com umidade natural variando entre igual ou superior a $12 \%$, que podem ser facilmente desagregados, misturados e extrudados, geralmente são processados pelo tipo de preparação denominado "via semi-úmida", [9].

O presente estudo considera a preparação de argila por via semi-úmida, pois esta é a mais utilizada em função da facilidade de trabalhar com os equipamentos que normalmente são: desintegradores, homogeneizadores e laminadores. As vantagens de utilização desse método são: processar argila tanto úmida como seca; menor manutenção dos equipamentos; obtenção de material granulado, reduzindo problemas de secagem e queima dos produtos acabados; o produto final é mais poroso; umidificação da argila mais padronizada [10].

Os desintegradores são equipamentos de aplicação primária ou de desbaste que inicia a trituração da argila. Sua função é, ao receber os torrões vindos do caixão alimentador reduzir sua granulometria até $5 \mathrm{~mm}$, medida ideal para entrar no laminador de desbaste, equipamento também utilizado no processo de preparação de massa [10].

Os homogeneizadores podem realizar moagem, mistura e compactação das argilas com muita qualidade, dificilmente alcançada por outros equipamentos. No processo de preparação de massa além da moagem realizada por ele, a primeira homogeneização ocorre neste equipamento, além do amassado. "Depois de esmagado e moído o material, o sistema de raspadeiras e braços do rotor removem o material intensamente criando uma melhor uniformidade" [10].

O laminador é um equipamento que trabalha com dois cilindros paralelos que giram em direções contrárias tendendo ao mesmo centro, em velocidades diferentes. $\mathrm{Na}$ preparação de massa sua principal função é moer a argila obtendo melhor aglutinação do material. Com a diferença de velocidades dos cilindros não há apenas o esmagamento da argila, mas também sofre um laminado ou desgarramento das partículas, contribuindo de forma substancial para o grau de homogeneização da massa [10].

Após todas as etapas da preparação de massa, o material segue para o estoque ficando de preferência coberto o que auxiliará no processo de sazonamento da argila. Esta estocagem pode ser feita em galpões fechados para evitar a lavagem da massa por chuva o que gera o carregamento do material, excesso de umidade e desperdício. Caso não haja a possibilidade do estoque coberto, pode-se utilizar plásticos ou lonas para cobrir o material, cuidando da drenagem do terreno onde ele se encontre evitando o carregamento por chuva e desperdício. Quanto mais tempo a argila puder ficar nestas condições melhor será seu sazonamento sendo melhores os resultados. Com estes procedimentos espera-se um uso mais racionalizado das argilas evitando o desperdício, gerando maior produtividade das jazidas. $\mathrm{O}$ uso de argila preparada pode gerar até $25 \%$ de aumento na produção [11]. Uma vez assegurado o padrão das argilas utilizadas, desde o controle na extração na jazida à sua estocagem e preparação da massa, fica garantido que as variações dimensionais atenderão às especificações das normas vigentes, a absorção de água se manterá em torno de $14 \%$ e as resistências mecânicas serão adequadas [1].

Outros benefícios estão associados à preparação de argila. Considera-se que em termos gerais, uma massa cerâmica adequadamente elaborada pode permitir economias de até $35 \%$ de energia elétrica, $20 \%$ de energia térmica, aumentos de produção de até $25 \%$, redução dos índices de deformação de até $40 \%$, aumentos importantes na qualidade de acabamento, evitando perdas e, portanto, resultando em economias adicionais de energia térmica e elétrica [12]. 
Métodos de análise de viabilidade econômico financeira

De acordo com [13], a análise de investimentos divide-se em dois grupos: Métodos Robustos, englobando os métodos que selecionam projetos; e Métodos Classificatórios, também chamados de Métodos de Corte, englobando os que geram indicadores para projetos já selecionados [13]. A Tabela I representa o grupo de métodos conforme a classificação citada.

Tabela I - Métodos de análise de investimentos.

[Table I - Methods of investment analysis.]

\begin{tabular}{ll}
\hline $\begin{array}{l}\text { Métodos } \\
\text { Robustos } \\
\text { de Análise de } \\
\text { Investimentos }\end{array}$ & $\begin{array}{l}\text { Método do Valor Presente Líquido } \\
\text { (VPL) }\end{array}$ \\
\cline { 2 - 2 } & $\begin{array}{l}\text { Método do Valor Anual Uniforme } \\
\text { Equivalente (VAUE) }\end{array}$ \\
\hline & $\begin{array}{l}\text { Método de Taxa Interna de Retorno } \\
\text { (TIR) }\end{array}$ \\
\cline { 2 - 2 } $\begin{array}{l}\text { Método do Índice Benefício/Custo } \\
\text { Classificatórios } \\
\text { e de Corte }\end{array}$ & $\begin{array}{l}\text { Método da Taxa de Retorno Contábil } \\
\text { (TRC) }\end{array}$ \\
\cline { 2 - 2 } & $\begin{array}{l}\text { Método do Período de Recuperação } \\
\text { de Capital (Pay-back) }\end{array}$ \\
\hline
\end{tabular}

Fonte: adaptado de [13]

Os métodos de avaliação de investimentos são utilizados para tomada de decisão que envolva certo nível de complexidade. Dessa forma, "fica, então, claro que somente problemas suficientemente importantes necessitam de métodos estruturados de tomar decisões" [14]. As situações a serem analisadas deverão apresentar as seguintes características:

1. Ser importantes para justificar o esforço de se utilizar um método estruturado.

2. A decisão não é óbvia; é necessário organizar o problema.

3. O aspecto econômico é significativo e influenciará na decisão.

A análise de viabilidade econômico-financeira neste estudo utiliza o Valor Presente Líquido - VPL, a Taxa Interna de Retorno - TIR e o Tempo de Recuperação do Capital Payback Descontado. Valor Presente Líquido ou Present Value "é um conceito matemático que indica o valor atual de uma série uniforme de capitais futuros, descontados a uma determinada taxa de juros compostos, por seus respectivos prazos" [15]. O Método de Taxa Interna de Retorno, abreviado como TIR, é a taxa de retorno de um determinado projeto "necessária para igualar o valor de investimento com seus respectivos fluxos de caixa futuro" [16]. A TIR é a taxa que retorna o Valor Líquido Presente de um fluxo de caixa igual à zero. [15] destaca que a TIR é um índice que indica a rentabilidade de um investimento por uma unidade de tempo. Denominado como Payback, o tempo de recuperação do capital, conhecido também como método do período de retorno do capital, "refere-se ao tempo decorrido entre o investimento inicial no momento o qual o lucro líquido acumulado se iguala ao valor desse investimento" [17]. Payback Descontado refere-se ao tempo necessário para que o capital seja recuperado juntamente com a taxa mínima de atratividade esperada pelo investidor. O Método do Valor Anual Uniforme Equivalente "é um método de análise de investimentos que trabalha no conceito de valor anual. Esse método é recomendado para comparação de projetos com vidas diferentes, pois utiliza uma base de tempo anual para confrontar as alternativas" [18]. O Método do Índice Benefício/Custo tem por objetivo, em parte, corrigir a deficiência do VPL e do VPL mensal, que é a de expressarem o retorno em valores absolutos. Além do mais é um indicador relativo e mede a expectativa de retorno para cada unidade de capital [19]. O Método da Taxa de Retorno Contábil é o método "que não leva em consideração o valor do dinheiro, da rentabilidade no tempo propriamente dita, e não considera também o fluxo de caixa [20]. Considera somente os valores contábeis". Estes três últimos métodos de análise de investimentos não serão aplicados neste estudo.

\section{Estudo de caso}

Aempresa estudada foi fundada no final da década de 1950 e encontra-se na terceira geração familiar. As informações foram adquiridas em visita à Indústria Cerâmica "Y", no

Tabela II - Investimento fixo em R $\$ 1,00$. [Table II - Fixed investment in $R \$ 1.00$.

\begin{tabular}{clccc}
\hline Item & \multicolumn{1}{c}{ Discriminação } & Qtd & Valor Unitário & Valor Total \\
\hline 1 & Construção de galpão & 1 & $200.000,00$ & $200.000,00$ \\
2 & Alimentador linear & 1 & $72.000,00$ & $72.000,00$ \\
3 & Laminador de desbaste & 1 & $90.000,00$ & $90.000,00$ \\
4 & Esteira transportadora & 4 & $24.000,00$ & $96.000,00$ \\
5 & Instalações elétricas e & 1 & $190.000,00$ & $190.000,00$ \\
& motores & & & $648.000,00$ \\
Total & & & &
\end{tabular}


município de Itaboraí, através de entrevista realizada com o Gestor principal, uma vez que a empresa é uma sociedade por quotas de responsabilidade limitada. Os nomes das pessoas e da indústria serão preservados por solicitação do Gestor. A metodologia utilizada foi uma pesquisa de campo feita através de entrevista com formulário para a obtenção das informações mínimas necessárias para o desenvolvimento da pesquisa. Foram utilizadas questões abertas [21]. Dentre as empresas no município de Itaboraí, a empresa "Y" foi escolhida por representar a média das demais em relação à produção, número de funcionários e localização, bem como espaço onde poderá ser implantada a preparação de argila o que ajuda a viabilizar o novo empreendimento por não ter necessidade de aquisição de nova área. A empresa atualmente ocupa uma área de $27.000 \mathrm{~m}^{2}$, sendo que a área coberta da cerâmica é de $18.000 \mathrm{~m}^{2}$. A produção se constitui de blocos de vedação, blocos estruturais e blocos para laje de cobertura. As medidas mais produzidas são $09 \times 19 \times 19 \mathrm{~cm}^{3}$, comercialmente conhecido como $20 \times 20$, e $09 \times 19 \times 29 \mathrm{~cm}^{3}$, comercialmente conhecido como $20 \times 30$. O bloco para laje tem a medida de $06 \times 25 \times 25 \mathrm{~cm}^{3}$. Outras medidas também são produzidas em me-nor escala: 11,5 x 11,5 x $24 \mathrm{~cm}^{3} ; 11,5 \times 19 \times 24 \mathrm{~cm}^{3}$;
$14 \times 19 \times 19 \mathrm{~cm}^{3} ; 14 \times 19 \times 39 \mathrm{~cm}^{3} ; 09 \times 19 \times 39 \mathrm{~cm}^{3}$. Todos os blocos atendem às especificações normativas apropriadas. Com os equipamentos da linha de produção e o forno existente, tem capacidade instalada para uma produ- ção mensal de até 1.600 milheiros do bloco do tamanho 09 x 19 x $19 \mathrm{~cm}^{3}$. Em função do mercado sua produção tem alcançado 1.300 milheiros deste bloco. Para a implantação da central de massa é necessário uma área coberta com galpão em estrutura metálica fechado nas laterais por parede de alvenaria, tendo duas aberturas uma em cada extremidade que terá formato retangular com a medida de pelo menos $1.000 \mathrm{~m}^{2}$. Dentro do galpão ficarão as máquinas e a matéria prima preparada. A empresa dispõe da área sendo apenas necessária a construção do galpão, o que representa redução também no investimento caso fosse preciso adquirir o terreno. A preparação de massa proporciona a diminuição do número de equipamentos na linha de produção. Atualmente a empresa tem sua linha de produção montada com os seguintes equipamentos: destorroador, dois alimentadores lineares, homogeneizador, misturador, laminador, extrusora, cortadeira. Entre cada equipamento, trabalham esteiras transportadoras levando a matéria prima. Com a implantação da preparação de

Tabela III - Receita e despesa em R\$.

[Table III - Revenue and expense in R\$.]

\begin{tabular}{ccccc}
\hline \multirow{2}{*}{ DESCRIÇÃO } & set/10 & out/10 & nov/10 & dez/10 \\
& $\mathrm{p} 1$ & $\mathrm{p} 2$ & $\mathrm{p} 3$ & $\mathrm{p} 4$ \\
\hline Receita & $201.530,66$ & $191.095,21$ & $203.190,54$ & $207.036,75$ \\
Despesa & $152.008,52$ & $137.539,80$ & $159.708,02$ & $169.317,86$ \\
Saldo & $49.522,14$ & $53.555,41$ & $43.482,52$ & $37.718,89$ \\
& & & & \\
\hline \multirow{2}{*}{ DESCRIÇÃO } & $\mathrm{jan} / 11$ & $\mathrm{fev} / 11$ & $\mathrm{mar} / 11$ & $\mathrm{abr} / 11$ \\
& $\mathrm{p} 5$ & $\mathrm{p} 6$ & $\mathrm{p} 7$ & $\mathrm{p} 8$ \\
\hline Receita & $198.090,20$ & $191.195,21$ & $213.193,23$ & $219.943,31$ \\
Despesa & $144.475,33$ & $125.332,81$ & $156.197,17$ & $166.271,73$ \\
Saldo & $53.614,87$ & $65.862,40$ & $56.996,06$ & $53.671,58$ \\
& & & & $\mathrm{j}$ \\
\hline \multirow{2}{*}{ DESCRIÇÃO } & $\mathrm{mai} / 11$ & $\mathrm{jun} / 11$ & $\mathrm{jul} / 11$ & $\mathrm{ago} / 11$ \\
& $\mathrm{p} 9$ & $\mathrm{p} 10$ & $\mathrm{p} 11$ & $\mathrm{p} 12$ \\
\hline Receita & $208.817,91$ & $210.566,61$ & $195.869,90$ & $210.056,59$ \\
Despesa & $153.037,50$ & $156.641,34$ & $140.317,83$ & $147.696,40$ \\
Saldo & $55.780,41$ & $53.925,27$ & $55.552,07$ & $62.360,19$ \\
& & & & $\mathrm{dez} / 11$ \\
\hline DESCRIÇÃO & $\mathrm{set} / 11$ & $\mathrm{put} / 11$ & $\mathrm{nov} / 11$ & $\mathrm{p} 16$ \\
\hline Receita & $255.252,66$ & $213.578,49$ & $236.317,57$ & $261.854,37$ \\
Despesa & $183.370,29$ & $155.295,80$ & $187.890,86$ & $213.813,32$ \\
Saldo & $71.882,37$ & $58.282,69$ & $48.426,71$ & $48.041,05$ \\
\hline
\end{tabular}

Fonte: autores. 
massa, poderão ser remanejados os seguintes equipamentos reduzindo assim o valor do investimento para a compra dos demais: o destorroador, um alimentador linear e o

Tabela IV - IPCA.

[Table IV - IPCA.]

\begin{tabular}{ccc}
\hline ANO & MÊS & \% \\
\hline \multirow{2}{*}{2010} & SET & 0,45 \\
& OUT & 0,75 \\
& NOV & 0,83 \\
& DEZ & 0,63 \\
& JAN & 0,83 \\
& FEV & 0,80 \\
& MAR & 0,79 \\
& ABR & 0,77 \\
& MAI & 0,47 \\
& JUN & 0,15 \\
& JUL & 0,16 \\
& AGO & 0,37 \\
& SET & 0,53 \\
& OUT & 0,43 \\
& NOV & 0,52 \\
& DEZ & 0,50 \\
\hline
\end{tabular}

Fonte:adapotado de [23]
Tabela VI - Fluxo de caixa deflacionado ou constante. [Table VI - Cash flow deflated or constant.]

\begin{tabular}{cccc}
\hline MÊS & $\begin{array}{c}\text { FLUXO } \\
\text { DE CAIXA } \\
\text { CORRENTE }\end{array}$ & $\begin{array}{c}\text { INFLAÇÃO } \\
\%\end{array}$ & $\begin{array}{c}\text { FLUXO } \\
\text { DE CAIXA } \\
\text { DEFLACIONADO }\end{array}$ \\
\hline set/10 & $49.522,14$ & 1,0045 & $49.300,29$ \\
out/10 & $53.555,41$ & 1,0075 & $53.156,73$ \\
nov/10 & $43.482,52$ & 1,0083 & $43.124,59$ \\
dez/10 & $37.718,89$ & 1,0063 & $37.482,75$ \\
jan/11 & $53.614,87$ & 1,0083 & $53.173,53$ \\
fev/11 & $65.862,40$ & 1,0080 & $65.339,68$ \\
mar/11 & $56.996,06$ & 1,0079 & $56.549,32$ \\
abr/11 & $53.671,58$ & 1,0077 & $53.261,47$ \\
mai/11 & $55.780,41$ & 1,0047 & $55.519,47$ \\
jun/11 & $53.925,27$ & 1,0015 & $53.844,50$ \\
jul/11 & $55.552,07$ & 1,0016 & $55.463,33$ \\
ago/11 & $62.360,19$ & 1,0037 & $62.130,31$ \\
set/11 & $71.882,37$ & 1,0053 & $71.503,40$ \\
out/11 & $58.282,69$ & 1,0043 & $58.033,15$ \\
nov/11 & $48.426,71$ & 1,0052 & $48.176,19$ \\
dez/11 & $48.041,05$ & 1,0050 & $47.802,04$ \\
TOTAL & $\mathbf{8 6 8 . 6 7 4 , 6 3}$ & & $\mathbf{8 6 3 . 8 6 0 , 7 5}$ \\
\hline
\end{tabular}

Fonte: autores.

Tabela V - Fluxo de caixa corrente.

[Table V-Cash flow stream.]

\begin{tabular}{ccccc}
\hline \multirow{2}{*}{ PERÍODO } & \multirow{2}{*}{ RECEITA } & \multicolumn{2}{c}{ CUSTOS } & FLUXO DE \\
& & FIXO & VARIÁVEL & CAIXA LIVRE \\
\hline SET/10 & $201.530,66$ & $-57.763,24$ & $-94.245,28$ & $49.522,14$ \\
OUT/10 & $191.095,21$ & $-42.637,34$ & $-94.902,46$ & $53.555,41$ \\
NOV/10 & $203.190,54$ & $-59.091,97$ & $-100.616,05$ & $43.482,52$ \\
DEZ/10 & $207.036,75$ & $-52.488,54$ & $-116.829,32$ & $37.718,89$ \\
JAN/11 & $198.090,20$ & $-55.898,66$ & $-88.576,67$ & $53.614,87$ \\
FEV/11 & $191.195,21$ & $-39.457,94$ & $-85.874,87$ & $65.862,40$ \\
MAR/11 & $213.193,23$ & $-58.992,12$ & $-97.205,05$ & $56.996,06$ \\
ABR/11 & $219.943,31$ & $-51.547,63$ & $-114.724,10$ & $53.671,58$ \\
MAI/11 & $208.817,91$ & $-46.867,36$ & $-106.170,14$ & $55.780,41$ \\
JUN/11 & $210.566,61$ & $-55.140,84$ & $-101.500,50$ & $53.925,27$ \\
JUL/11 & $195.869,90$ & $-51.268,21$ & $-89.049,63$ & $55.552,06$ \\
AGO/11 & $210.056,59$ & $-55.410,41$ & $-92.285,99$ & $62.360,19$ \\
SET/11 & $255.252,66$ & $-63.540,99$ & $-119.829,30$ & $71.882,37$ \\
OUT/11 & $213.578,49$ & $-55.136,65$ & $-100.159,15$ & $58.282,69$ \\
NOV/11 & $236.317,57$ & $-72.476,78$ & $-115.414,08$ & $48.426,71$ \\
DEZ/11 & $261.854,37$ & $-59.555,39$ & $-154.257,93$ & $48.041,05$ \\
TOTAL & $3.417 .589,21$ & $-877.274,07$ & $-1.671 .640,52$ & $868.674,62$ \\
\hline
\end{tabular}

Fonte: autores. 
Tabela VII - Fluxo de caixa previsto.

[Table VII - Expected cash flow.]

\begin{tabular}{|c|c|c|c|c|c|c|c|c|c|}
\hline Período & \multirow{2}{*}{$\begin{array}{l}\begin{array}{l}\text { Fluxo de } \\
\text { Caixa }\end{array} \\
58.871,45\end{array}$} & \multicolumn{2}{|c|}{ Período } & \multirow{2}{*}{$\begin{array}{l}\begin{array}{l}\text { Fluxo de } \\
\text { Caixa }\end{array} \\
72.650,81\end{array}$} & \multicolumn{2}{|c|}{ Período } & \multirow{2}{*}{$\begin{array}{l}\begin{array}{l}\text { Fluxo de } \\
\text { Caixa }\end{array} \\
65.761,13\end{array}$} & Período & \multirow{2}{*}{$\begin{array}{c}\begin{array}{c}\text { Fluxo de } \\
\text { Caixa }\end{array} \\
79.540,49\end{array}$} \\
\hline jan & & \multirow{12}{*}{$\underset{\sim}{\stackrel{\Xi}{\sim}}$} & Jan & & \multirow{12}{*}{$\stackrel{m}{\stackrel{2}{\sim}}$} & jan & & Jan & \\
\hline fev & $59.445,59$ & & Fev & $73.224,95$ & & fev & $66.335,27$ & Fev & $80.114,63$ \\
\hline mar & $60.019,73$ & & Mar & $73.799,09$ & & mar & $66.909,41$ & Mar & $80.688,77$ \\
\hline $\mathrm{abr}$ & $60.593,87$ & & Abr & $74.373,23$ & & $\mathrm{abr}$ & $67.483,55$ & Abr & $81.262,91$ \\
\hline mai & $61.168,01$ & & Mai & $74.947,37$ & & mai & $68.057,69$ & Mai & $81.837,05$ \\
\hline$\cong$ jun & $61.742,15$ & & Jun & $75.521,51$ & & jun & $68.631,83$ & $\cong$ Jun & $82.411,19$ \\
\hline$\sim$ jul & $62.316,29$ & & Jul & $76.095,65$ & & jul & $69.205,97$ & Jul & $82.985,33$ \\
\hline ago & $62.890,43$ & & Ago & $76.669,79$ & & ago & $69.780,11$ & Ago & $83.559,47$ \\
\hline set & $63.464,57$ & & Set & $77.243,93$ & & set & $70.354,25$ & Set & $84.133,61$ \\
\hline out & $64.038,71$ & & Out & $77.818,07$ & & out & $70.928,39$ & Out & $84.707,75$ \\
\hline nov & $64.612,85$ & & Nov & $78.392,21$ & & nov & $71.502,53$ & Nov & $85.281,89$ \\
\hline dez & $65.186,99$ & & Dez & $78.966,35$ & & dez & $72.076,67$ & Dez & $85.856,03$ \\
\hline
\end{tabular}

Fonte: autores.

Tabela VIII - Fluxo de caixa por cenários.

[Table VIII - Cash flow through scenarios.]

\begin{tabular}{|c|c|c|c|c|c|c|c|c|}
\hline \multirow[b]{2}{*}{ Período } & \multicolumn{3}{|c|}{ CENÁRIOS } & \multirow{2}{*}{\multicolumn{2}{|c|}{ Período }} & \multicolumn{3}{|c|}{ CENÁRIOS } \\
\hline & Otimista & $\begin{array}{c}\text { Mais } \\
\text { Provável }\end{array}$ & Pessimista & & & Otimista & $\begin{array}{c}\text { Mais } \\
\text { Provável }\end{array}$ & Pessimista \\
\hline jan & $61.815,02$ & $58.871,45$ & $55.927,87$ & \multirow{12}{*}{$\stackrel{\nabla}{\stackrel{\sim}{\nu}}$} & jan & $76.283,35$ & $72.650,81$ & $69.018,26$ \\
\hline fev & $62.417,86$ & $59.445,59$ & $56.473,31$ & & fev & $76.886,19$ & $73.224,95$ & $69.563,70$ \\
\hline mar & $63.020,71$ & $60.019,73$ & $57.018,74$ & & mar & $77.489,04$ & $73.799,09$ & $70.109,13$ \\
\hline abr & $63.623,56$ & $60.593,87$ & $57.564,17$ & & $\mathrm{abr}$ & $78.091,89$ & $74.373,23$ & $70.654,56$ \\
\hline mai & $64.226,41$ & $61.168,01$ & $58.109,60$ & & mai & $78.694,73$ & $74.947,37$ & $71.200,00$ \\
\hline$\simeq$ jun & $64.829,25$ & $61.742,15$ & $58.655,04$ & & jun & $79.297,58$ & $75.521,51$ & $71.745,43$ \\
\hline ¿ jul & $65.432,10$ & $62.316,29$ & $59.200,47$ & & jul & $79.900,43$ & $76.095,65$ & $72.290,86$ \\
\hline ago & $66.034,95$ & $62.890,43$ & $59.745,90$ & & ago & $80.503,27$ & $76.669,79$ & $72.836,30$ \\
\hline set & $66.637,79$ & $63.464,57$ & $60.291,34$ & & set & $81.106,12$ & $77.243,93$ & $73.381,73$ \\
\hline out & $67.240,64$ & $64.038,71$ & $60.836,77$ & & out & $81.708,97$ & $77.818,07$ & $73.927,16$ \\
\hline nov & $67.843,49$ & $64.612,85$ & $61.382,20$ & & nov & $82.311,82$ & $78.392,21$ & $74.472,59$ \\
\hline dez & $68.446,33$ & $65.186,99$ & $61.927,64$ & & dez & $82.914,66$ & $78.966,35$ & $75.018,03$ \\
\hline \multirow{12}{*}{$\stackrel{m}{\stackrel{n}{\sim}}}$. & $69.049,18$ & $65.761,13$ & $62.473,07$ & \multirow{12}{*}{$\stackrel{n}{i}$} & jan & $83.517,51$ & $79.540,49$ & $75.563,46$ \\
\hline & $69.652,03$ & $66.335,27$ & $63.018,50$ & & fev & $84.120,36$ & $80.114,63$ & $76.108,89$ \\
\hline & $70.254,88$ & $66.909,41$ & $63.563,93$ & & mar & $84.723,20$ & $80.688,77$ & $76.654,33$ \\
\hline & $70.857,72$ & $67.483,55$ & $64.109,37$ & & $\mathrm{abr}$ & $85.326,05$ & $81.262,91$ & $77.199,76$ \\
\hline & $71.460,57$ & $68.057,69$ & $64.654,80$ & & mai & $85.928,90$ & $81.837,05$ & $77.745,19$ \\
\hline & $72.063,42$ & $68.631,83$ & $65.200,23$ & & jun & $86.531,74$ & $82.411,19$ & $78.290,63$ \\
\hline & $72.666,26$ & $69.205,97$ & $65.745,67$ & & jul & $87.134,59$ & $82.985,33$ & $78.836,06$ \\
\hline & $73.269,11$ & $69.780,11$ & $66.291,10$ & & ago & $87.737,44$ & $83.559,47$ & $79.381,49$ \\
\hline & $73.871,96$ & $70.354,25$ & $66.836,53$ & & set & $88.340,29$ & $84.133,61$ & $79.926,92$ \\
\hline & $74.474,80$ & $70.928,39$ & $67.381,97$ & & out & $88.943,13$ & $84.707,75$ & $80.472,36$ \\
\hline & $75.077,65$ & $71.502,53$ & $67.927,40$ & & nov & $89.545,98$ & $85.281,89$ & $81.017,79$ \\
\hline & $75.680,50$ & $72.076,67$ & $68.472,83$ & & dez & $90.148,83$ & $85.856,03$ & $81.563,22$ \\
\hline
\end{tabular}


Tabela IX - Resultados.

[Table IX - Results.]

\begin{tabular}{cccc}
\hline \multirow{2}{*}{ Métodos } & \multicolumn{3}{c}{ CENÁRIOS } \\
\cline { 2 - 4 } & OTIMISTA & MAIS PROVÁVEL & PESSIMISTA \\
VPL & $\mathrm{R} \$ 2.278 .256,82$ & $\mathrm{R} \$ 2.112 .075,23$ & $\mathrm{R} \$ 2.038 .079,70$ \\
TIR & $10,31 \%$ & $9,83 \%$ & $9,35 \%$ \\
Payback Descontado & 11,02 meses & 11,62 meses & 12,4 meses \\
\hline Fonte: autores.
\end{tabular}

homogeneizador.

A Tabela II lista, quantifica e orça o conjunto de obras, máquinas e equipamentos para a implantação da central de preparação de massa. São apresentados os itens que não constam na estrutura da cerâmica para se evitar valores superestimados em relação ao investimento total e conseqüente redução dos índices de rentabilidade [22].

\section{Dados financeiros}

Para análise de viabilidade econômico-financeira, foram levantadas as informações, com base nos balancetes, referentes ao período de setembro de 2010 a dezembro de 2011. A Tabela III apresenta as receitas e despesas da instituição analisada, no período acima citado onde se encontram os valores mensais, expressos em Reais.

A estrutura de custos diretos dos produtos da empresa apresenta contas referentes aos gastos com matéria prima, combustível para o forno, energia elétrica, combustíveis e lubrificantes, fretes e carretos. Os custos de pessoal referemse a salários pagos aos funcionários, as contribuições legais referentes à contratação e demissão de colaboradores, cesta básica, entre outros. A receita apresentada refere-se à venda dos blocos cerâmicos nos diversos modelos produzidos pela empresa. Não estão incluídas as receitas não operacionais e outras receitas possíveis como, por exemplo, a receita oriunda da venda de créditos de carbono que ocorre ocasionalmente. Os custos fixos encontrados referem-se a todos os valores apropriados para a manutenção das atividades da empresa independente da produção. São valores realizados no período e que englobam entre outras contas: o consumo de energia elétrica fora da produção, os salários da administração e pessoal de apoio, honorários, taxas, etc. Os custos variáveis são valores referentes ao período analisado, atribuídos ao processo produtivo da indústria. Estão reunidos nestes custos os valores referentes à matéria prima utilizada na fabricação dos blocos, o combustível consumido no forno para queima dos blocos, os salários da produção, a energia elétrica consumida na produção, entre outros. O fluxo de caixa para o empreendimento foi corrigido no período estudado pelo IPCA - Índice de Preços ao Consumidor Amplo, apurado pelo SNIPC - Sistema nacional de Preços ao Consumidor. Sua abrangência geográfica inclui a Região Metropolitana do Rio de Janeiro, onde se encontra o município de Itaboraí. Sua periodicidade é mensal [23].

A Tabela IV apresenta o IPCA no período de setembro de 2010 a dezembro de 2011 mês a mês.
A Tabela $\mathrm{V}$ apresenta o fluxo de caixa do intervalo de tempo estudado, levantado mensalmente. Importante destacar que a indústria cerâmica pesquisada é uma empresa de pequeno porte, classificada no regime tributário denominado SIMPLES Nacional. Tributo este instituído pelo decreto $\mathrm{n}^{\circ} 6.541$, de 12 de maio de 2008 [24].

A Tabela VI apresenta o fluxo de caixa corrente, a inflação mensal no período de setembro de 2010 a dezembro de 2011 e o fluxo de caixa deflacionado.

Utilizou-se o fluxo de caixa deflacionado a partir dos dados atuais para fazer a regressão e montar o fluxo de caixa projetado para o período de 48 meses, igual ao período de tempo para quitação do empréstimo. A partir dele optou-se por realizar dois tipos de regressão para o cálculo do fluxo de caixa previsto: uma linear e outra função potência. Foi considerado o menor erro padrão de estimativa. Assim sendo, foi escolhida a função linear para efetuar a estimativa do fluxo de caixa conforme apresentado na Tabela VII. Utilizou-se planilha eletrônica $(E x c e l)$ para cálculo dos valores.

A Tabela VIII mostra o fluxo de caixa previsto em três tipos de cenários possíveis: otimista, mais provável e pessimista. Para o cenário mais provável considerou-se o fluxo de caixa previsto, feito com base na regressão. O cenário otimista foi calculado com base no cenário mais provável acrescentando $5 \%$ e o pessimista foi calculado reduzindo $5 \%$ do cenário mais provável.

$\mathrm{O}$ valor total do investimento será captado com agente financeiro, uma vez que a empresa declarou não ter disponível o valor total do investimento. Consultou-se o Banco do Brasil S/A e após diversas análises de linhas de crédito existentes, foi escolhida a linha de financiamento denominada Cartão BNDES, por ser o recurso oriundo deste Banco, com juros de $0,89 \%$ ao mês. Esta linha de crédito tem valor máximo de financiamento de R $\$ 700.000,00$ (setecentos mil reais) para empresas com faturamento anual de até R \$ 3.600.000,00 (três milhões e seiscentos mil reais). Não há carência para a amortização. Para quitação antecipada do empréstimo, o Banco não conta com uma taxa de desconto específica. Em caso de antecipação do pagamento, será considerado o saldo devedor e a taxa de desconto ficará em função do número de parcelas restantes.

Algumas condições serão exigidas à empresa como: possuir conta corrente no Banco do Brasil; no momento da assinatura de formalização do empréstimo nenhum dos dirigentes da empresa, que precisarão apresentar seus documentos de identificação, não poderão ter restrições 
impeditivas, assim como no momento da liberação do recurso. A empresa não pode constar no CADIN - Cadastro Nacional de Inadimplentes e precisa apresentar os seguintes documentos: CND - Certidão de Débitos Negativos, CRF Certidão de Regularidade do FGTS e Certidão Conjunta de Tributos. Será exigido também a RAIS - Relação Anual de Informações Sociais.

\section{ANÁLISE DOS RESULTADOS}

Utilizaram-se os métodos tradicionais de análise de viabilidade econômico-financeira VPL, TIR e Payback Descontado, para verificar se o projeto será aceitável ou não, considerando os três cenários previstos: otimista, mais provável, pessimista. As taxas mínimas de atratividade utilizadas foram: para o cenário otimista uma taxa de desconto de $0,85 \%$ ao mês; no cenário mais provável a taxa de desconto admitida foi a mesma taxa de juros do empréstimo, $0,89 \%$ ao mês; e para o cenário pessimista a taxa de desconto é de $1 \%$ ao mês. Lançando os valores do fluxo de caixa previsto para os três cenários na planilha eletrônica específica e utilizando as fórmulas determinadas encontram-se os valores conforme a Tabela IX.

De acordo com a Tabela IX, observa-se que o Valor Presente Líquido - VPLé positivo. A Taxa Interna de Retorno - TIR está acima das Taxas Mínimas de Atratividade - TMA, nos três cenários. Dessa forma, do ponto de vista econômico e financeiro, a instalação da central de preparação de massa apresenta-se como viável. O tempo de recuperação do capital também está muito atrativo, acontecendo antes de completar um ano da capitação do recurso. Mostrando-se como viável a realização do empreendimento, destaca-se alguns detalhes que serão necessários caso a empresa opte por realizá-lo. Um estudo mais aprofundado sobre a quantidade de argila que a empresa vai consumir caso a demanda por blocos cerâmicos aumente deve ser considerada, pois a central de preparação de massa prevista atende a atual produção da fábrica. Para ampliação do parque fabril a empresa deverá contar com a autorização da Prefeitura Municipal de Itaboraí, já que aumentará a área ocupada atualmente. A capacidade do transformador instalado deverá ser revista em função da instalação de novos equipamentos e também sobre um possível aumento da produção, considerando um cenário otimista, embora a empresa trabalhe aquém da sua capacidade total.

\section{CONCLUSÕES}

Com a viabilização econômico-financeira, a empresa em foco poderá adquirir o recurso e seguindo as etapas apresentadas implantar a central de preparação de massa, com retorno do capital em tempo razoável. Importante destacar que outros benefícios a esta ação não foram contabilizadas, como por exemplo, a eficiência da secagem dos produtos, a sinterização mais uniforme, as dimensões dos blocos bem definidas, a redução de energia térmica e elétrica, entre outros. A empresa conseguirá manter suas atividades com um consumo de argila mais eficiente podendo aumentar a produtividade o que também contribuirá para os resultados contábeis. A metodologia usada poderá ser utilizada em qualquer outra empresa do mesmo seguimento na cidade de Itaboraí, considerando que os problemas evidenciados são comuns e as soluções, adequadas a cada tamanho de fábrica, também podem ser compartilhadas.

\section{REFERÊNCIAS}

[1] G. A. Parkesian, M. M. Soares, "Alvenaria estrutural em blocos cerâmicos: projeto, execução e controle", O nome da Rosa, S. Paulo, SP (2010) 24.

[2] ABNT, Associação Brasileira de Normas Técnicas, Norma 15270-1:2005, "Blocos cerâmicos para alvenaria", Rio de Janeiro, RJ: ABNT (2005) 1.

[3] T. Ercio, C. V. M. Filho, F. R. Cleto, "Código de práticas $n^{\circ}$ 1: alvenaria de vedação em blocos cerâmicos", S. Paulo: IPT - Instituto de Pesquisas Tecnológicas do Estado de S. Paulo, SP (2009) 1.

[4] G. Roberta, "Fatores envolvidos no sazonamento e suas implicações nas propriedades de argilas para a indústria cerâmica", Tese em Engenharia de Metalúrgica e de Materiais, Rio de Janeiro, Universidade Federal do Rio de Janeiro - COPPE (2006).

[5] M. R. Brochado, "Inovação Tecnológica na Indústria de Cerâmica Vermelha: Estudo de viabilidade técnico econômico da cerâmica vermelha estrutural de alta porosidade - padrão alemão", R. Janeiro, RJ (2001).

[6] A. A. Oliveira, Tecnologia em cerâmica, Editora Lara, R. Janeiro, RJ (2011).

[7] J. A. C. Bouth, "Manual de operações básicas na indústria de cerâmica vermelha", FastGraf, Natal, Brasil (2008).

[8] Verdés, "Máquinas e Instalações", disponível em: http:// verdes.com.br, acesso em 11/2011.

[9] J. V. Emiliano, Guia de utilização de resíduos na indústria da cerâmica vermelha, Editora Senai, R. Janeiro, RJ (2006). [10] Verdes, "Máquinas e Instalações. Preparação de argilas para fábricas de produtos da cerâmica vermelha", Itú, S. Paulo, SP (2011) 16.

[11] R. S. E. C. Tapia, Manual para a indústria de cerâmica vermelha, $2^{\mathrm{a}} \mathrm{Ed}$. Vol. 2, SEBRAE/RJ. R. Janeiro, RJ (2005). [12] L. F. Pacheco, A. B. A. Pacheco, "Manual do uso eficiente da energia elétrica em indústrias de cerâmica vermelha: orientações para empresários do segmento de cerâmica vermelha no uso racional da energia elétrica", SEBRAE/RJ, R. Janeiro, RJ (2009).

[13] I. Jadovski, "Diretrizes técnicas e econômicas para usinas de reciclagem de resíduos de construção de demolição", Diss. Mestrado em Engenharia, Porto Alegre, Universidade Federal do Rio Grande do Sul, RS (2005).

[14] N. Csasarotto Filho, N. Kopittke, B. Hartmut, Análise de investimentos: matemática financeira, engenharia econômica, tomada de decisão, estratégia empresarial, $9^{\mathrm{a}}$. Ed. Atlas, S. Paulo, SP (2000).

[15] L. H. F. Marquezan, “Análise de investimento", Rev. Eletr. Contabilidade III, 1 jan-jun (2006). 
[16] B. Wottrich, "Modelo para a análise econômica e financeira em projetos de geração distribuída de energia com fontes alternativas", Diss. Mestrado em Engenharia Elétrica, Santa Maria, Universidade Federal de Santa Maria, RS (2010).

[17] A. T. Souza Junior, "Análise de viabilidade econômica: implantação de uma indústria cerâmica vermelha de pequeno porte no estado do Pará", Disponível em http://www. eumed.net/cursecon/ecolat/br/11/jmspa.html, acessado em $11 / 01 / 2012$.

[18] A. G. Feldens, C. J. Muller, T. P. Filomena, F. J. Klieman Neto, A. S. Castro, M. J. Anzanello, "Política para avaliação e substituição de frota por meio da adoção de modelo multicritério", disponível em http://www.unisinos. br/abcustos/_pdf/171.pdf, acessado em 21/03/2014.

[19] V. C. Silva, "Análise de projetos de investimentos", Monografia, Disponível em http://www.avm.edu.br/ docpdf/monografias_publicadas/k212778.pdf, acessado em
$21 / 03 / 2014$

[20] C. L. Kreuz, A. Souza, "Custos de produção, expectativas de retorno e de risco do agronegócio do alho no sul do Brasi", Associação Brasileira de Custos, disponível em http://www. unisinos.br/abcustos/_pdf/ABC_KreuzSouza.pdf, acessado em 21/03/2014.

[21] J. A. Ruiz, Metodologia cientifica: guia para eficiência nos estudos, 6a. Ed. Atlas, S. Paulo, Brasil (2011).

[22] SEBRAE - Serviço Brasileiro de apoio às Micro e Pequenas Empresas, "Série perfil de projetos: produtos cerâmicos", Vitória, ES (1999).

[23] IBGE, Disponível em http://www.ibge.gov.br/home/ estatistica/indicadores/precos/inpc_ipca/defaultinpc.shtm. acessado em 01/05/2012.

[24] BRASIL, disponível em http://www.receita.fazenda. gov.br/Legislacao/Decretos/2008/dec6451.htm, acessado em $01 / 05 / 2012$.

(Rec. 21/08/2013, Rev. 14/04/2014, Ac. 14/07/2014) 